\title{
SITUACIÓN DEL BOVINO CRIOLLO LECHEROTROPICAL (CLT) EN MÉXICO, NICARAGUA Y COSTA RICA
}

\author{
STATUS OF TROPICAL DAIRY CREOLE (CLT) IN MEXICO, NICARAGUA \\ AND COSTA RICA
}

\begin{abstract}
Vilaboa Arroniz, J. ${ }^{* *}$, Quirós Madrigal, O.J. ${ }^{2}$, Díaz Rivera, P. ${ }^{1}$ y Zetina Córdoba, P. ${ }^{3}$
${ }^{1}$ Colegio de Postgraduados. Campus Veracruz. Veracruz. México. *jvilaboa@colpos.mx

${ }^{2}$ Centro de Investigación Económica y Desarrollo Agroempresarial (CIEDA). Facultad de Ciencias Agroalimentarias. Ciudad Universitaria Rodrigo Facio. San Pedro, San José. Costa Rica.

${ }^{3}$ Universidad Politécnica de Huatusco. Unidad Académica de Biotecnología y Agroindustrial. Huatusco, Veracruz. México.
\end{abstract}

\section{Palabras claVe adicionales}

Razas autóctonas. EEAVM. CATIE. AMCROLET.

\section{RESUMEN}

Los bovinos Criollos Lecheros Tropicales (CLT) se consideran un grupo racial nativo de América, con un buen potencial para la producción lechera a base de pastos. Estas razas presentan un menor volumen de producción, pero con una mayor calidad (sólidos totales) y resistencia al estrés de los climas tropicales, en comparación con otras razas especializadas (Holstein y Jersey) que han ido sustituyendo paulatinamente a estas nativas con fines productivos. El inventario del CLT, Reyna o Lechero Centroamericano, se estima en unos 900-1000 ejemplares, y aunque no existen reportes de su aportación a la producción de leche, se considera que su conservación y desarrollo es de vital importancia como proceso productivo alterno en hatos bovinos del trópico. El objetivo del presente trabajo fue realizar una semblanza de los CLT en tres países latinoamericanos.

\section{SUMMARY}

The Criollo Lechero Tropical (CLT) bovines are considered a racial group native to America, with good potential for milk production based on pasture. These breeds have a lower production volume, but higher milk quality (total solids) and resistance to stress in tropical climates, compared with other specialized breeds (Holstein and Jersey) which have replaced progressively these native breeds

\section{AdDitiONAL KEYWORDS}

Native breeds. EEAVM. CATIE. AMCROLET. for productive purposes. The inventory of CLT Reyna o Tropical Dairy is estimated between 9001000 individuals, and although there are no reports of its contribution to milk production, it its considered that their conservation and development is of vital important as alternative production process in cattle herds in the tropics. The aim of this study was to develop a profile of CLT cattle in three latinoamerican countries.

\section{INTRODUCCIÓN}

En Centroamérica, la producción lechera se basa principalmente en la utilización de material genético (pie de cría y semen) importado de USA y Canadá a través de empresas comerciales, siendo Costa Rica y El Salvador los principales usuarios (Ministerio de Agricultura y Ganadería, 2003). La principal finalidad ha sido la especialización de la ganadería con fines netamente productivos; no obstante, las razas utilizadas (Holstein y Jersey, principalmente) no han podido generar los volúmenes óptimos requeridos ni reproducirse satisfactoriamente en los climas tropicales (Santellano et al., 2011). Así, el uso excesivo de razas provenientes de otras latitudes ha alterado las 


\section{VILABOA ARRONIZ, QUIRÓS MADRIGAL, DÍAZ RIVERA Y ZETINA CÓRDOBA}

características de los bovinos nativos, ya que se considera que el potencial productivo de éstos no justifica su utilización (Pariacote, 2000; López et al., 2009). Según Segura y Montes (2001), el reemplazo de razas nativas por especializadas se produjo a consecuencia de la intensificación de los sistemas de producción; ello, justificado en la necesidad de satisfacer la demanda de alimentos originada por el crecimiento poblacional, además del desinterés de los productores y la moda por el uso de nuevas razas con mayor demanda comercial (Ministerio de Agricultura, Ganadería y Alimentación, 2003).

Para el caso de Centroamérica, dicha sustitución comenzó en la década de los 50's (SIMAS, 1990) con la utilización de las razas Holstein y Jersey para los sistemas especializados, mientras que para los sistemas semi-intensivos y de doble propósito se utilizaron diversos cruces de genotipos, que iban desde $\mathrm{F} 1$ hasta los $5 / 8$ Bos taurus 3/8 Bos indicus (Tewolde, 2007). Dichos cruces generaron complementariedad y vigor híbrido (heterosis), que en su momento se reflejaron satisfactoriamente en sus indicadores productivos y reproductivos (López et al., 2009); sin embargo, con el transcurso del tiempo, estas características (complementariedad y vigor híbrido) se fueron desperdiciando por el poco control entre los cruzamientos de las razas especializadas con las cebuínas, y que generó una gran diversidad de grados de cruzamiento en los hatos (FAO, 2003). Además, con dichos cruces (Bos taurus x Bos indicus) se buscaba asegurar la producción mediante la adaptación de los bovinos a los climas tropicales (De Alba, 2007a; Tewolde, 2007); sin embargo, al lograr mayor producción, mediante el aprovechamiento del alto potencial genético, se perdió resistencia al medio (Pariacote, 2000). Desde el punto de vista técnico, a diferencia del doble propósito caracterizado por el ordeño manual, en los sistemas de confinamiento y semi-confinamiento se requiere cierto nivel tecnoló- gico y de especialización, que representa altos costos (Izaguirre et al., 2007; Vargas, 2008; Santellano et al., 2011) y que para el caso de Centroamérica se ha calculado que significan más del $40 \%$ de los costos de producción, principalmente por concepto de alimentación, mediante la utilización de concentrados (Cámara Nacional de Productores de Leche, 2011); situación contraria a la recomendación de la alimentación en pastoreo de los bovinos en el trópico (De Alba, 2007b). El objetivo del presente trabajo fue realizar una semblanza del Criollo Lechero Tropical o Lechero Centroamericano(CLT) en el contexto de la ganadería centroamericana, con la finalidad de documentar, con base a una revisión bibliográfica, sus características, distribución y esfuerzos para la conservación.

\section{ORÍGENES DE LAS RAZAS CRIOLLAS LECHERASTROPICALES}

Las razas criollas lecheras han sido muy importantes para el desarrollo de la ganadería en el trópico, ya que constituyeron los hatos fundadores de la misma y fueron la base de los hatos latinoamericanos durante más de 500 años (Müller-Haye y Gelman, 1981). Según Villalobos et al. (2009), la actividad bovina en Centroamérica se inicia en el año 1521, con la importación de bovinos de Santo Domingo, por Pedro Arias de Ávila, y la influencia de estos ejemplares se ha manifestado en los hatos criollos de Centroamérica y México; por su parte Ossa et al. (2011) mencionan que los criollos latinoamericanos provienen de los bovinos europeos que arribaron a la isla La Española a partir de 1493; por su parte, Soares et al. (2011), sostienen que se desconoce específicamente el origen de los bovinos traídos por los conquistadores. Sin embargo, se presume que los bovinos ibéricos sean los ancestros de los criollos en el continente americano o, tal vez, pudiese existir un paralelismo entre ambos (Fernández y Barba, 2005); por su parte, Rouse (1997) menciona 
que los ejemplares Bos taurus que arribaron al conteniente descendían del Bos taurus primigenius, que fue domesticado durante la revolución agrícola del neolítico en Oriente Medio y Europa Oriental.

Se considera como ganado criollo a los bovinos (Bos taurus) descendientes de los originalmente traídos de Europa, principalmente de España, durante los años posteriores a la conquista, los cuales se adaptaron evolutivamente y se reprodujeron en diferentes regiones agroecológicas de América (Fernández y Barba, 2005; Villalobos et al., 2009).

\section{EL CRIOLLOLECHEROTROPICAL}

El Criollo Lechero Tropical (CLT), también conocido en Centroamérica como Reyna o Lechero Centroamericano, es una raza formada por bovinos provenientes de Nicaragua (Santellano et al., 2011); aunque el mayor inventario se encuentra, actualmente, en México (AMCROLET, 2010). El primer hato conocido se originó en la década de 1920 en la zona de Rivas, Nicaragua, con ejemplares Bos taurus procedentes de España e introducidos por Belalcázar durante la conquista, en el siglo XIV (Rouse, 1977; De Alba, 2011). El cambio en el uso del término Lechero Centroamericano a Reyna se hace en honor de Don Joaquín Reyna (criador del primer hato) (De Alba, 2011; Vilaboa et al., 2012). Por su parte, la Asociación Mexicana de Criadores de Ganado Romosinuano y Lechero Tropical A.C. (AMCROLET) registró la expresión Criollo Lechero Tropical(CLT) en su Acta Constitutiva, para la utilización de dicho nombre (AMCROLET, 1998). Es importante señalar que, la denominación Criollos Lecheros Tropicales se refiere a un grupo de razas, a los que les une un origen común y fuerzas selectivas similares en la época en que se crearon, con un parecido fenotípico y funcional en la actualidad (De Alba, 2011). Por tanto, son diferentes estirpes las que reciben la denominación de Criollos Lecheros
Tropicales, incluidas los Reyna de Nicaragua. Este grupo ha contribuido, de forma muy importante, en la conformación de los hatos criollos de Centroamérica; donde este tipo de ganado se denomina, indistintamente, como CLT, Reyna o Lechero Centroamericano.

Este Bos taurus, nativo de Centroamérica, se considera especializado para la producción de leche a base de pastos y con requerimiento de pocos insumos, además de presentar un acervo genético que le ha permitido su adaptación a entornos agroecológicos extremos, así como, una gran resistencia, tanto al estrés generado por el clima tropical como a los parásitos (Fernández y Barba, 2005; González et al., 2009; Santellano et al., 2011).

\section{DESCRIPCIÓNYCARACTERÍSTICAS DE LA RAZA}

Según Primo (1992) y la AMCROLET (1998b, 2005), la estampa del CLT debe ser angulosa, particularmente en el cuello y la cruz, con un amplio arco de costillas; de pronunciada masculinidad en machos y feminidad en hembras, pelo corto (menos de $3 \mathrm{~mm}$ ) escaso y brillante, piel gruesa y pigmentada, arrugas alrededor de los ojos, cuello y frente; canal del parto amplio, inserción de la cola descarnada, borla de la cola con muy escaso pelo; manto bayo o rojo con o sin cabos negros, los overos sólo se admiten a nivel de $3 / 4$ de pureza (AMCROLET, 1998). El peso a $1^{\circ}, 2^{\circ}, 3^{\circ} \mathrm{y}$ $4^{\circ}$ parto en hembras debe ser $360,375,425$ y $450 \mathrm{~kg}$, respectivamente, y en toros adultos de 500 a $750 \mathrm{~kg}$. Esta raza presenta una producción media de leche por lactación estandarizada a 305 días de 1110 a $1180 \mathrm{~kg}$, con apoyo del becerro; una lactancia media de 318 días y 100 días entre el parto y la concepción; la edad al primer parto es de 1222 días y el intervalo entre partos de 455 días (Rosendo y Becerril, 2002). Según la AMCROLET, dicha raza basa su selección en la sumatoria de lactancias completas a 


\section{VILABOA ARRONIZ, QUIRÓS MADRIGAL, DÍAZ RIVERA Y ZETINA CÓRDOBA}

305 días de ordeño; por ello, recomienda el pesaje de la leche, individualmente, cada 21-28 días. El CLT puede producir leche con mayor contenido de nutrientes, pero presenta menor volumen de producción (Tewolde, 2007).

\section{DISTRIBUCIÓNDEL CLTEN CENTROAMÉRICA}

Los informes de la FAO sobre el estado de los recursos zoogenéticos en Centroamérica (FAO-SAGARPA, 2002; FAO, 2004a; Hidalgo et al., 2004) reportan que el CLT se ubica principalmente en México, que concentra el mayor inventario; Nicaragua donde se originó el primer núcleo y Costa Rica, uno de los principales importadores y exportadores de semen (Fornos, 2006; Vargas, 2008; Santellano et al., 2011). En estos países, la raza está localmente adaptada pero con una escasa utilización en los sistemas ganaderos. Por su parte, el resto de los países centroamericanos (Guatemala, El Salvador, Honduras y Panamá) no presentan información respecto al CLT (FAO, 2003; FAO, 2004b, Ministerio de Agricultura y Ganadería, 2003; Ministerio de Agricultura, Ganadería y Alimentación, 2004).

\section{El CAsode México}

En México el uso del CLT se inició en la década de 1960 con las importaciones de vacas, sementales y semen de Nicaragua y Costa Rica. El primer hato se estableció en el estado de Tamaulipas, en un predio de la Asociación Mexicana de Producción Animal(AMPA); posteriormente, se distribuyó a otros estados como Veracruz, Michoacán y Guerrero, siendo en estos cuatro estados donde se ha encontrado más información con referencia al manejo de la raza. Actualmente, los hatos de CLT, enfocados básicamente a selección y mejoramiento genético, son manejados por la AMCROLET (FAOSAGARPA, 2002); Asociación que se enfoca al respaldo y declaración de las genealogías, expedición de certificados indivi- duales, comparación de valores genéticos entre hatos y control de registros e inventarios. Dicha organización, en el 2010 , contaba con un inventario de 1657 bovinos registrados y 88 socios (activos y no activos) conformados por instituciones y productores, principalmente de México y con algunos miembros de Nicaragua y Costa Rica. El inventario del hato fundador, en 2010, correspondía al 3\% del total (AMCROLET, 2010). En los últimos tiempos, el hato criollo más importante se localiza en Veracruz, México, bajo la dirección técnica de los Dres. Carlos Becerril y Adalberto Rosendo (De Alba, 2011).

\section{El caso de Nicaragua}

En Nicaragua, donde destaca el lote reproductor de Doña Socorro, Vda. de Reyna descendiente del primer hato de la ganadería de la Flor, ubicado en la bahía del mismo nombre (de Alba, 2011); el inventario actual se encuentra distribuido en los municipios y/o departamentos de Masaya, Rivas, Chinandega, Muy Muy, Camoapa, Managua, Matagalpa y León. El hato de Don Joaquín Reyna tuvo influencia sobre varios núcleos de los criollos lecheros del trópico; de hecho algunos de los toros que han mostrado más alto rango en las evaluaciones genéticas realizadas en México, provienen del núcleo de Rivas (De Alba, 2011).

Se estima que hay alrededor de 1500 bovinos, de los cuáles, aproximadamente, 500 son ejemplares puros. En 1998, la raza fue nombrada patrimonio nacional y su cuidado y gestión corre a cargo de la Universidad Nacional Agraria (UNA) (Fornos, 2006; Rubio, 2008). Al igual que en México, el ganado CLT se ha enfocado a la selección y a su mejoramiento genético para la producción de leche.

\section{El caso de Costa Rica}

En Costa Rica, según datos de la FAO sobre el estado de los recursos zoogenéticos, no existe inventario sobre la población de CLT (Hidalgo et al., 2004). El ma- 
nejo de la raza estuvo a cargo del Centro Agronómico Tropical de Investigación y Enseñanza(CATIE)(Casas y Tewolde, 2001).

Vargas (2008) menciona que la importancia de esta raza en el país se debió a la exportación de semen por parte del Centro Agronómico Tropical de Enseñanza e Investigación (CATIE). Las exportaciones se iniciaron en 1955, con el apoyo de la Fundación Rockefeller, que fue la primera en desarrollar trabajos con dicha raza; sin embargo, el impacto que tuvo en los sistemas ganaderos locales fue bastante reducido.

En el padrón de AMCROLET (2010), la Estación Experimental Alfredo Volio Mata (EEAVM) de la Universidad de Costa Rica y el CATIE se encuentran registrados como socios de dicha Asociación. Por su parte, Vilaboa et al. (2012) reportan que dichas instituciones desecharon el uso del CLT y optaron por el uso de otras razas o cruces Bos taurus $\mathrm{x}$ Bos indicus para la producción de leche, relegando en importancia la utilización del CLT. El manejo de la raza pasó de las instituciones a los productores ubicados en la provincia de Guanacaste, donde sólo se encontró un hato puro con 14 vientres y diversos ejemplares cruzados, con Jersey, principalmente. El inventario, entre cruces con CLT y puros, pudiera ser que no fuera superior a los 100 ejemplares, distribuidos, además, entre un reducido número de productores.

\section{CONSERVACIÓN DE LA RAZA Y ESTUDIOSREALIZADOS}

ElCLT recibió apoyo internacional para su estudio y preservación (FAO, 2004a). Éste consistió en el establecimiento de hatos con fines de estudio en Universidades y Centros de investigación, y en menor medida con fines productivos en Asociaciones de productores; por tanto, los esfuerzos de conservación han sido escasos y no han generado el impacto deseado entre los productores, que continúan con cruzamientos indiscriminados entre el ganado criollo, cebú y razas europeas (Wilkins, 1991; De Alba, 2007a; Vilaboa et al., 2012). Aunado a ello, la falta de seguimiento en dichos programas no ha generado información concreta sobre el CLT y, a su vez no se ha logrado una gran difusión entre los productores. Por ejemplo, el reemplazo de la raza en instituciones de Costa Rica, debido a condicionantes políticos, legales y/o productivos, y la poca difusión de la raza entre los productores, ha conducido prácticamente a su desaparición en el país (Rubio, 2008; Vilaboa et al., 2012). Por otra parte, en Nicaragua, la conservación de semen (cerca de 5000 dosis) que se había logrado en la década de 1980, ha carecido de resultados por falta de seguimiento (FAO, 2004a). A su vez, en México, la AMCROLET cuenta con información sobre parámetros productivos y reproductivos, pero no ha podido desarrollar un esquema más amplio de promoción y difusión de la raza.

Según De Alba (2007b), existió un consenso entre las instituciones latinoamericanas que decidieron el uso del CLT, en cuanto al establecimiento de objetivos comunes para la obtención y estudio de los parámetros productivos y reproductivos así como para impulsar la participación de los productores en el uso de esta raza.

Sobre elCLT, según Vilaboa et al. (2011a, $2011 \mathrm{~b}$ ), se han realizado investigaciones para determinar su selección y mejoramiento genético; comportamiento reproductivo, respuesta al calor; resistencia a ectoparásitos, características de la leche y sus derivados, producción y composición de la leche, comparación con otras razas lecheras pero se carece de estudios sobre los componentes tecnológicos utilizados en los ranchos con bovinos CLT, así como las características socioeconómicas de los productores que utilizan que esta raza y la percepción éstos sobre la misma.

\section{ORGANIZACIÓNDEPRODUCTORES}

En cuanto a la organización de los pro- 


\section{VILABOA ARRONIZ, QUIRÓS MADRIGAL, DÍAZ RIVERA Y ZETINA CÓRDOBA}

ductores, en 1998 se formó la Asociación Mexicana de Criadores de Ganado Romosinuano y Criollo Lechero Tropical (AMCROLET), organismo que asocia a 88 productores (activos y no activos) principalmente de México, y en menor grado de Nicaragua y Costa Rica con los objetivos del mejoramiento genético de la raza, control de registros e inventarios, certificación de genealogías y comparaciones de valores genéticos entre hatos. En 2010 , esta asociación reportaba un inventario superior a los 1600 bovinos, donde el $3 \%$ correspondía al hato referencia (machos y hembras); $2 \%$ hato fundación machos, $47 \%$ hato fundación hembras; $10 \%$ hato nacencias machos y $34 \%$ hato nacencias hembras (AMCROLET, 2010).

La AMCROLET (1998) reconoce la presencia histórica de varios hatos afines que han participado en la fundación y perfeccionamiento de los ejemplares inscritos. En primer lugar se encuentran los bovinos originarios o descendientes del hato de Don Joaquín Reyna en Rivas, Nicaragua y semen importado de este país, así como, bovinos certificados por el Registro Genealógico de Ganado de Nicaragua (RGGN). Asimismo, reconoce animales y semen proveniente del CATIE, que desechó el uso de la raza, y el Registro Genealógico de Ganado de Costa Rica y Honduras (RGGC) (FAO, 2004b). De igual forma, admite ejemplares que se encuentran en México y los de selección que utiliza CIMPA en la República Dominicana y Guatemala; otros núcleos afines, se encuentran en Colombia, Venezuela y Bolivia, que estuvieron bajo restricción por problemas de la fiebre aftosa (AMCROLET, 1998).

En Centroamérica, los resultados que se han obtenido sobre la raza CLT se han enfocado al mejoramiento genético, por lo que se requiere un avance en el manejo integral que permita una mayor participación de los ganaderos (FAO, 2004a y b); para ello se requieren políticas coherentes con el sector pecuario, ya que los países centroamericanos tendrían que determinar y especificar la manera en que se insertarían las razas criollas en la producción, evitando el antagonismo entre la visión productivista y aquella que considera el valor de conservación de las razas nativas en cada país.

Vázquez (2005) considera de gran importancia la conservación de las razas criollas por su variabilidad en el germoplasma que podría utilizarse con fines sanitarios y productivos; sin embargo, su incorporación ha sido limitada a los sistemas productivos (Vaughan et al., 2005) a pesar de que la utilización de éstas podrían mostrar ventajas en comparación con las razas comerciales (Holstein) para la elaboración de productos lácteos (Meza et al., 2012). Por su parte, López et al. (2009) mencionan que los cruces Bos taurus x Bos indicus podrían ser una buena alternativa para la producción de leche en el trópico, y que dichos cruces, en comparación con las razas locales, reportarían una mayor producción de leche y mejores condiciones reproductivas. Sin embargo, requieren de mayor suministro de alimentos. En este sentido, Vilaboa et al. (2012) también argumentan que, la utilización de cruces de CLT con otros Bos taurus pueden representar una óptima estrategia para la producción de leche en zonas tropicales. No obstante, el enfoque productivista actual ha conllevado la disminución en el uso de las razas nativas con tendencias a la extinción, ya que, por desconocimiento, se ignora su potencial y características (adaptabilidad, mansedumbre y resistencia) que podrían aportar para la producción de leche en el trópico.

Recientemente, se ha documentado que la raza CLT presenta mayores frecuencias del alelo $B$ de las $\alpha$-lactoglobulinas que están asociadas a las mayores concentraciones de grasa y proteína de la leche; mientras que el alelo A esta asociado a mayor producción de leche (Meza et al., 2012). Esta característica es de gran importancia en el valor de conservación de la raza. 


\section{CONCLUSIÓN}

El Criollo Lechero Tropical (CLT) se considera un grupo racial nativo de Centroamérica con un buen potencial para la producción de leche bajo sistemas de pastoreo tradicionales, además de soportar el estrés calórico y la resistencia a los parásitos; sin embargo ha sido poco utilizada en los sistemas ganaderos, ya sea por desconocimiento o por falta de difusión de la raza. Tan sólo Nicaragua, México y Costa Rica reportan inventarios de esta raza, habiendo estado su manejo a cargo, principalmente, de instituciones y centros de investigación. En Nicaragua la

\section{BIBLIOGRAFÍA}

AMCROLET. 1998b. Asociación Mexicana de Criadores de Ganado Romosinuano y Criollo Lechero Tropical. Reglamento técnico de la Asociación Mexicana de Criadores de ganado Romosinuano y Lechero tropical. AMCROLET. $12 \mathrm{pp}$.

AMCROLET. 2005. Asociación Mexicana de Criadores de Ganado Romosinuano y Criollo Lechero Tropical. Manual de procedimientos para inspectores de registro de las razas Criollo Lechero Tropical y Romosinuano para colaboradores de la AMCROLET. $15 \mathrm{pp}$.

AMCROLET. 2010. Asociación Mexicana de Criadores de Ganado Romosinuano y Criollo Lechero Tropical. Archivo inventario bovino octubre 2010. AMCROLET. Veracruz, México. 34 pp.

Cámara Nacional de Productores de Leche. 2011. Información del sector ganadero. http://www. proleche.com/info_sector.htm. (04/05/2011).

Casas, E y Tewolde, A. 2001. Evaluación de características relacionadas con la eficiencia reproductiva de genotipos criollos lecheros en el trópico húmedo. Arch Latinoam Prod Anim, 9: 63-67.

De Alba, J. 2007a. Resistencia a enfermedades y adaptación de ganados criollos de América al ambiente tropical.. Departamento de Agricultura. FAO. 3 pp. www.produccion-animal.com.ar. (01/03/2011).

De Alba, J. 2007b. El ganado lechero tropical en raza se considera patrimonio nacional, y su manejo está a cargo de instituciones y de productores independientes. En México se encuentra a cargo de la AMCROLET; $\mathrm{y}$, en Costa Rica, el CLT prácticamente ha desaparecido. Finalmente, es importante resaltar el elevado valor de conservación de estas razas, por la excelente calidad de su leche y como posible reservorio de una gran cantidad de genes valiosos o únicos.

\section{AGRADECIMIENTOS}

Al Food Security Center de la Universidad de Hohenheim, Alemania, por la beca otorgada para la pasantía postdoctoral.

América Latina. Departamento de Agricultura. FAO. 3 pp. www.produccion-animal.com.ar. (01/12/2010).

De Alba, J. 2011. Los Criollos Lecheros Tropicales. In: El libro de los Bovinos Criollos de América, J. de Alba Martínez. Biblioteca Básica de Agricultura (Colegio de Postgraduados). Ediciones Papiro Omega S.A. de C.V. México, D.F. pp. 92-98.

FAO-SAGARPA. 2002. Informe sobre la situación de los recursos genéticos pecuarios de México. www.sagarpa.gob.mx/.../InfoRGPecuariosM.aspx. (15/05/2011).

FAO. 2003. Informe sobre la situación de los recursos zoogenéticos en Panamá. 59 pp. ftp:/ /ftp.fao.org/docrep/fao/011/a1250f/annexes/ CountryReports/Panama.pdf. (21/06/2011).

FAO. 2004a. Informe sobre el estado de los recursos zoogenéticos en Nicaragua. 54 pp. ftp:// ftp.fao.org/docrep/fao/010/a1250e/annexes/ CountryReports/Nicaragua.pdf. (22/05/2011).

FAO. 2004b. Evaluación de la situación de la biodiversidad pecuaria de Honduras. $65 \mathrm{pp}$. ftp://ftp.fao.org/docrep/fao/010/a1250e/ annexes/CountryReports/Honduras.pdf. (07/ 06/2011).

Fernández, J.A. y Barba, C. 2005. Paralelismo entre las razas criollas americanas y las razas autóctonas españolas. Arch Zootec, 54: 135139. 


\section{VILABOA ARRONIZ, QUIRÓS MADRIGAL, DÍAZ RIVERA Y ZETINA CÓRDOBA}

Fornos, S. 2006. Estudio económico de la actividad ganadera del departamento de Rivas. Ministerio Rivas, Nicaragua. 71 pp. www.programasgtz. org.ni/files/public acion/1. (09/06/2011).

González, F., Becerril, C., Torres, G. and Díaz, P. 2009. Ticks infesting body regions of tropical milking criollo cattle in Veracruz, Mexico. Agrociencia, 43: 11-19.

Hidalgo, C., Monge, C., Cruz., A., Molina, J.R., Camacho, J., Vargas, G. y Barrientos, O. 2004. Informe parcial del país sobre la situación nacional de los recursos zoogenéticos. Subcomisión nacional encargada de la elaboración del informe país sobre la situación de los recursos genéticos pecuarios de Costa Rica. Ministerio de Agricultura. San José, Costa Rica. 43 pp.

Izaguirre, F., Martínez, J., Sánchez, L., Ramón, M., Pérez, P. y Martínez, G. 2007. Influencia del amamantamiento y presencia del toro en comportamiento productivo y reproductivo de vacas pardo suizo en el trópico húmedo. Rev Cient, 17: 614-620.

López, R., Vite, C., García, J.G. y Martínez, P.A. 2009. Reproducción y producción de leche de vacas con distinta proporción de genes Bos taurus. Arch Zootec, 58: 683-694.

Meza, M.A., González, A.F., Becerril, C.M., Rosendo, A., Díaz, P., Ruíz, F. y Vallejo, B. 2012. Relación de las variantes $A$ y $B$ de la $\alpha$ lactoglobulina con la producción y composición de la leche de vacas Holstein y Criollo Lechero Tropical. Agrociencia, 46: 15-22.

Ministerio de Agricultura y Ganadería. 2003. Diagnóstico de los recursos zoogenéticos en el Salvador. Nueva San Salvador. El Salvador. C.A. 75 pp.

Ministerio de Agricultura, Ganadería y Alimentación. 2004. Informe sobre la situación de los recursos zoogenéticos en Guatemala. http:// www.fao.org/ag/againfo/programmes/en/ genetics/documents/Interlaken/countryreports/ Guatemala.pdf. 65 pp. (23/06/2011).

Müller-Haye, B. y Gelman, J. (Eds). 1981. Recursos genéticos animales en América Latina. FAO. Roma, Italia. Folleto 22. 177 pp.

Ossa, G., Abuabara, Y., Pérez, J.E. y Martínez, G. 2011. El ganado Criollo colombiano Costeño con Cuernos (CCC). Anim Genetic Resources, 48: 101-107.

Pariacote, F. 2000. Riesgos de extinción del con- glomerado nativo de genes bovinos en América Latina: Caso Venezuela. Arch Zootec, 49: 1726.

Primo, A.T. 1992. El ganado bovino ibérico en las Américas: 500 años después. Arch Zootec, 41 (extra): 421-432.

Rosendo, A. and Becerril, C.M. 2002. Productive performance and genetic parameters in the tropical milking Criollo cattle in Mexico. Proc. $7^{\text {th }}$ World Congress Genetic Applied Livestock Production. Montpellier, France. Commun $\mathrm{N}^{\circ}$ 25-25.

Rouse, J.E. 1977. The Criollo Spanish cattle in the Americas. University of Oklahoma Press. Oklahoma. 303 pp.

Rubio, A. 2008. Caracterización técnica y económica de la raza de ganado Reyna en la Finca El Pino, Rivas, Nicaragua. Tesis. Escuela Agrícola Panamericana, El Zamorano. Honduras. 24 pp. Disponible en: http://zamo-oti02.zamorano.edu/ tesis_infolib/2008/T2657.pdf. (27/06/2011).

Santellano, E., Becerril, C., Yu Mei, C., Gianola, D., Torres, G., Ramírez, R., Domínguez, J. y Rosendo, A. 2011. Caracterización de la lactancia y evaluación genética del ganado Criollo Lechero Tropical utilizando un modelo de regresión aleatoria. Agrociencia, 45: 165-175.

SIMAS. 1990. Sistema de Información Mesoamericana sobre Agricultura Sostenible. Chelitas contra Chapiollas. Revista Enlace, 4: 17-19. http://www.simas.org.ni/revistaenlace/articulo/53. (01/03/2011).

Segura, J.C. y Montes, R.C. 2001. Razones y estrategias para la conservación de los recursos genéticos animales. Rev Biomed, 12: 196-206.

Soares, M.C., Soares, R., Lage, G., Jacomini, L., Silva, V., Gómes, M. y Oliveira, F. 2011. Conservación del bovino Curraleiro: cuantificación del censo y caracterización de los criadores. Animal Genetic Resources, 48: 109-116.

Tewolde, A. 2007. Los Criollos bovinos y los sistemas de producción animal en los trópicos de América Latina. XX reunión Asociación Latinoamericana de Producción Animal (ALPA). Perú. 7 pp.

Vargas, C. 2008. Comparación de ganancias de peso en bovinos Reyna-Jersey y Jersey, durante la etapa de desarrollo. Mesoamericana, 19: 227-232.

Vaughan, B., Rojas, E. y Quesada, L. 2005. Diálogo 
sobre recursos genéticos animales en la agricultura: la necesidad de su conservación y mejora para lograr sistemas de producción competitivos en Mesoamérica. Memoria. Montelimar. Nicaragua. 5 al 7 de diciembre de 2005.

Vázquez, A. 2005. Conservación y utilización de las razas bovinas criollas y colombianas para el desarrollo rural sostenible. Arch Zootec, 54: 141-144.

Vilaboa, J., Keating, N., Bautista, R., Díaz, P., Pérez, P. y Quirós, O. 2011a. El Criollo Lechero Tropical (CLT) en el contexto de la ganadería mexicana. Segunda parte. Fundación Produce Veracruz A.C. Agroentorno, 135: 23-25. http:/ /www.funprover.org/agroentorno/index.asp. (18/02/2012).

Vilaboa, J., Keating, N., Bautista, R., Díaz, P.,
Pérez, P. y Quirós, O. 2011b. El Criollo Lechero Tropical (CLT) en el contexto de la ganadería mexicana. Primera parte. Fundación Produce Veracruz A.C. Agroentorno no 134:28-29. http:/ /www.funprover.org/agroentorno/index.asp. (07/01/2012).

Vilaboa, J., Díaz, P., Quirós, O., Wingching, R., Zetina, P. 2012. Los sistemas ganaderos con Criollo Lechero Tropical (Reyna) en Costa Rica. Agronomía Mesoamericana, 23: 12.

Villalobos, A.I., Martínez, A.M y Delgado, J.V. 2009. Historia de los bovinos en Panamá y su relación con las poblaciones de bovinos de Iberoamérica. Arch Zootec, 58 (R): 121-129.

Wilkins, J. 1991. Special regional problems of breeding resources Latin American and Caribbean examples. In: Cattle Genetic Resources. World Anim Sci, B7: 91-122. 